\title{
Um ponto de convergência do olhar. Axiologia nas obras de Gentile e Klimt
}

\author{
Antonio Herci Ferreira Júnior ${ }^{7}$ \\ Edson Leite ${ }^{2}$ \\ DOI 10.20396/eha.vil4.3348
}

Este ensaio interpreta duas obras: Coronation of the Virgin ${ }^{3}$ (1420), de Gentile da Fabriano (1370-1427) e O beijo ${ }^{4}$ (1908), de Gustav Klimt (1861-1918). Separadas por séculos, essas obras utilizam três aspectos que nos permitem a aproximação: o uso de folhas de ouro; utilização de padrões nos preenchimentos de objetos e vestimenta e a retratação da mulher face a face com o homem. Estes aspectos, articulados expressivamente, permitem acompanhar as relações entre instâncias indissociáveis do valor: sua materialidade, representação e normatividade na contrição do corpo.

Do abstrato ao figurativo e deste de volta àquele

A história da arte, malgrado fundada em uma ideia geral de continuidade, apresenta momentos de crise, onde um sistema de valores ou técnicas mostra um esgotamento em sua carga expressiva enquanto outro sistema de valores ou teorias se fortalece, em tendência e potência. Nesses momentos críticos, alguns temas são recorrentes e retornam em acalorados debates. Um dos temas mais recorrentes e quase sempre no centro dessas crises é o embate ou confrontação entre o figurativo e o abstrato, em um movimento de pró-ao-contra, como se a figuração ou a abstração, em algum momento, saturasse sua própria potencialidade estética e remetesse ao seu contrário, ou por superexposição ou banalização da figura ou da abstração do mundo, como um dos sintomas de crise.

Os quinhentos anos que separam as obras parecem dobrar-se sobre si mesmos ao procurarem respostas para uma mesma questão: como figurar o mundo? Como expressá-lo para que a obra se realize como experiência do próprio mundo?

\footnotetext{
1 PGEHA - Programa de Pós-graduação Interunidades em Estética e História da Arte, Universidade de São Paulo. Doutorando e Mestre em Artes. Bacharel em Filosofia, FFLCH/USP. Bolsista, Agência de Fomento: CAPES.

2 PGEHA - Programa de Pós-graduação Interunidades em Estética e História da Arte, Universidade de São Paulo. Prof. Dr. e Coordenador do PGEHA.

3 FABRIANO, Gentile da. Coronation of the Virgin. Têmpera e ouro sobre madeira, $93 \mathrm{~cm} \times 64.1 \mathrm{~cm}$. Los Angeles: The ]. Paul Getty Museum, 1420 .

- Figura 1 -

4 KLIMT, Gustav. O beijo. Óleo e folha de ouro sobre tela, $180 \mathrm{~cm} \times 180 \mathrm{~cm}$. Viena: Österreichische Galerie Belvedere, 1908. — Figura 2 -
} 
Em ambos os pintores, a opção pela pintura diagramática não é por desconhecimento da técnica figurativa ou naturalista, mas uma busca da forma mais adequada para expressar um olhar que coloca em primeiro plano, para aquém do reconhecimento visual ou retratista do mundo, a expressão de valores que transcendem o que devem figurar e que são figurados como aparatos de reconhecimento da efetividade de sua aplicação.

\section{Gentile}

Christiansen ${ }^{5}$ situa dois marcos no desenvolvimento pictórico de Gentile: (i) Coronation OfThe Virgin (Brera, Milan, 1400) ${ }^{6}$ e (ii) Adoration of the Magi (Uffizi, Florence, 1423) ${ }^{7}$. Na primeira obra utiliza "todo o repertório técnico do artesão medieval" ${ }^{8}$ para criar uma superfície variada, por exemplo "nas línguas em chamas que emanam do Cristo e da Virgem". No segundo "um naturalismo novo e de longo alcance reformulou o conteúdo pictórico"10.

Segundo Christiansen, Coronation Of The Virgin estaria mais próxima desta segunda fase, malgrado seja designada como Gótica Internacional e colocada muitas vezes como contraponto do próprio renascimento. Essa proximidade com o naturalismo pode ser ainda ser mais fortemente percebida em outra obra que lhe faria par, na série composta para ser montada como um estandarte cerimonial de dupla face.

A ideia da aparência original das pinturas pode ser fornecida pelo padrão processional na Galleria Nazionale, em Perugia, também por um artista de Fabriano, mostrando de um lado a Madonna e a criança e no outro [verso do estandarte] a Anunciação. As pinturas da Cetty [Coronation] e de Caminati [Stigmatization] devem ter seguido um padrão semelhante: um dano retangular na base de cada painel seria assim o resultado de uma montagem comum em um estandarte onde poderiam ser carregadas. ${ }^{11}$

\footnotetext{
5 CHRISTIANSEN, Keith. "The Coronation of the virgin by Centile da Fabriano". In: J. Paul Getty Museum Journal: Volume 6-7/1978-1979. Los Angeles: Cetty Publications, 1979, página 5. [Disponivel em: http://www.getty.edu/publications/virtuallibrary/0892360186.html].

6 FABRIANO, Gentile da. Coronation of the Virgin with Saints. Tempera on panel, $157,2 \mathrm{~cm} \times 79,6 \mathrm{~cm}$ central panel; $117,5 \mathrm{~cm} \times 40 \mathrm{~cm}$ lower side panels; $48,9 \mathrm{~cm} \times 37,8 \mathrm{~cm}$ upper side panels. Milão: Pinacoteca di Brera, Room XXII, 1408. [Disponível em: https://pinacotecabrera.org/en/collezioneonline/opere/valle-romita-polyptych/].

7 FABRIANO, Gentile da. Adoration of the Magi. Têmpera e ouro sobre madeira, $300 \mathrm{~cm} \times 282 \mathrm{~cm}$. Florence: Galleria degli Uffizi, 1423. [Disponível em: https://www.uffizi.it/en/artworks/adoration-of-the-magi].

8 CHRISTIANSEN, Keith. The Coronation of the Virgin by Gentile Da Fabriano. página 5. Traduções minhas, texto original entre colchetes após as referências. ["the entire repertory of the medieval craftsman's technique"].

9 Ibid. ["in the tongues of flames emanating from the Christ and the Virgin"].

10 Ibid. ["a new and far-reaching naturalism has re-shaped the pictorial content"].

11 Ibid., página 3. ["An idea of the paintings" original appearance is provided by a processional standard in the Galleria Nazionale at Perugia, also by a Fabrianese artist, showing on one side the Madonna and Child, and on the other the Annunciation. The Getty and Carminati paintings must have formed a similar standard: a rectangular damage at the base of each panel would thus be the result of a common mount by which they could be carried on a pole."].
} 


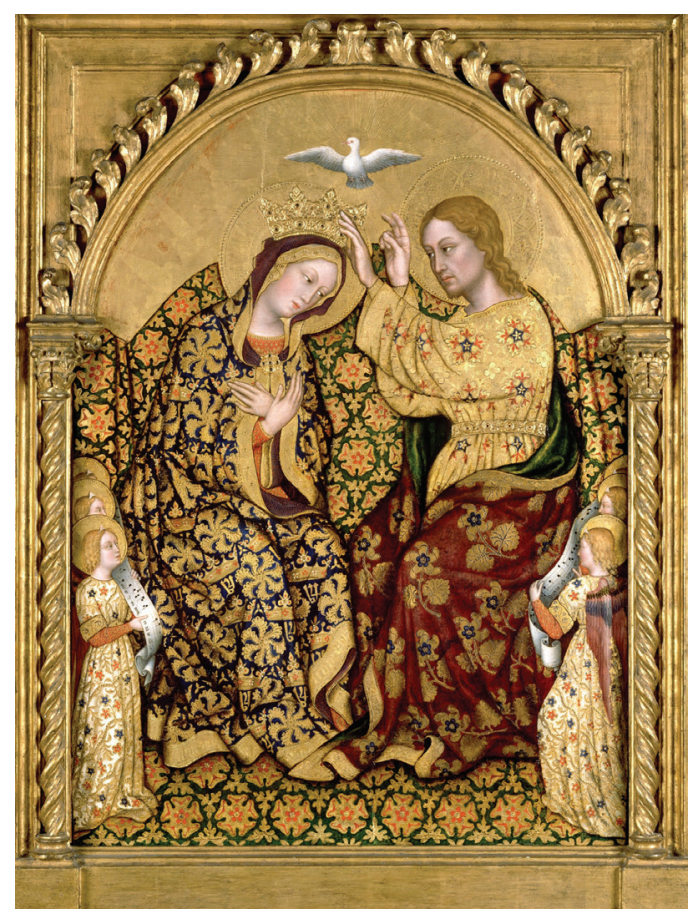

[Figura 1] FABRIANO, Centile da (1370-1427). Coronation of the Virgin.

Têmpera e ouro sobre madeira, Los Angeles: The ]. Paul Cetty Museum, 93cm X 64cm, 1420. [Imagem @ Wikimedia Commons]

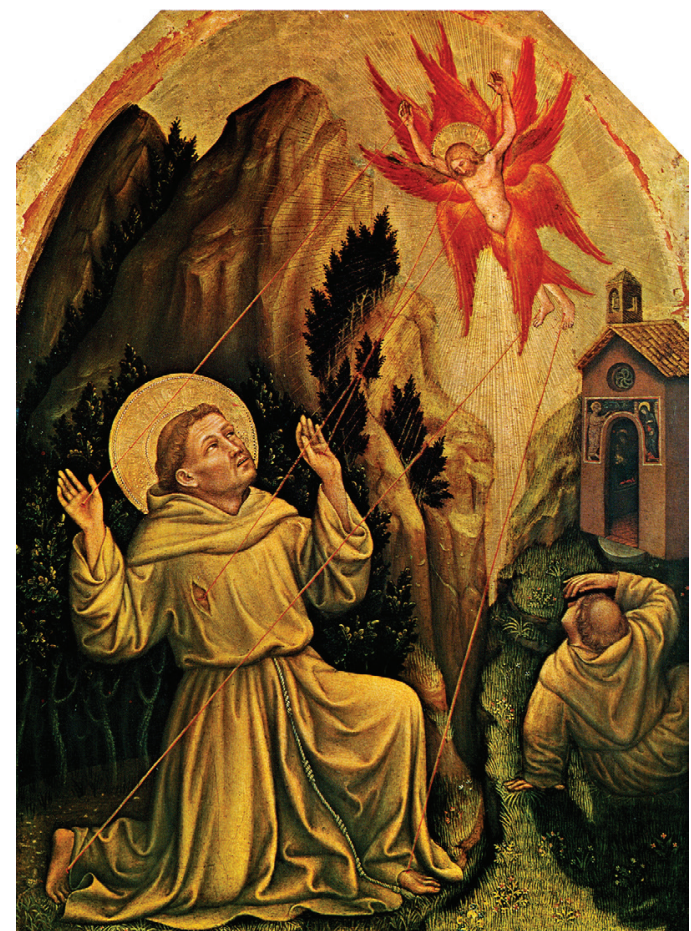

[Figura 3] FABRIANO, Gentile da. Stigmatization of St. Francis. 1420.

Têmpera e ouro sobre madeira, 93 X $64.1 \mathrm{~cm}$. Milão: Caminati Collection. [Imagem @ Wikimedia Commons]

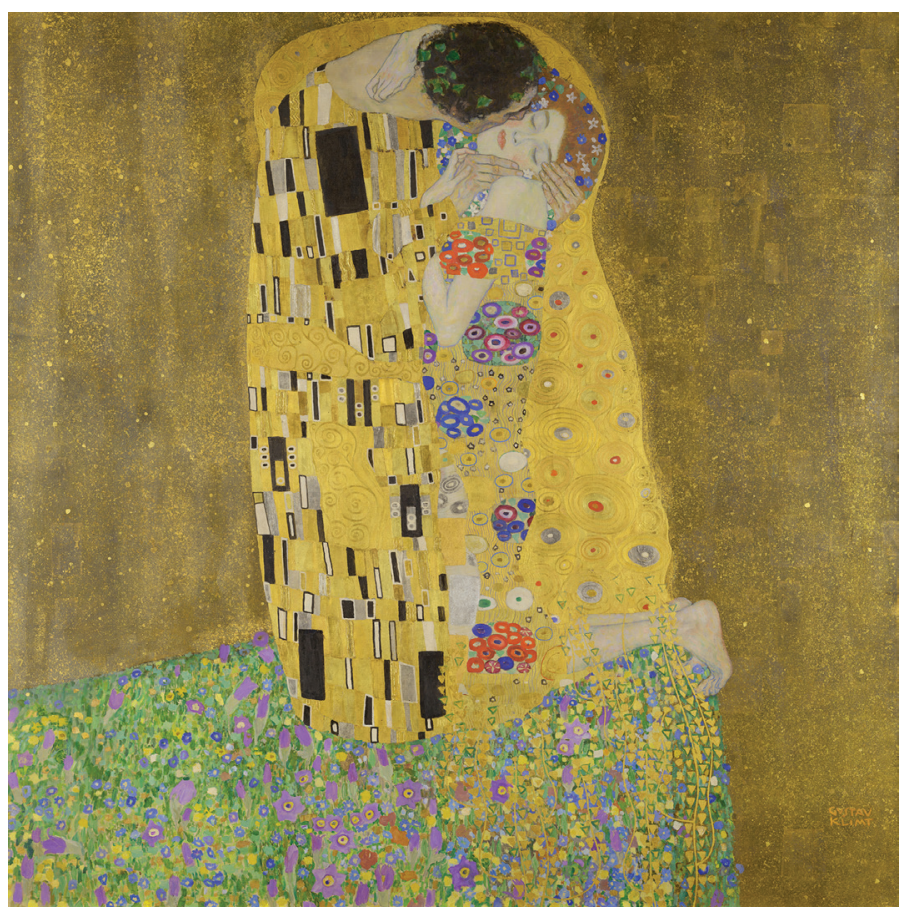

[Figura 2] KLIMT, Gustav (1861-1918). O beijo.

Óleo e folha de ouro sobre tela. Viena: Österreichische Galerie Belvedere, $180 \mathrm{~cm} \times 180 \mathrm{~cm}, 1908$. [Imagem @ Wikimedia Commons]

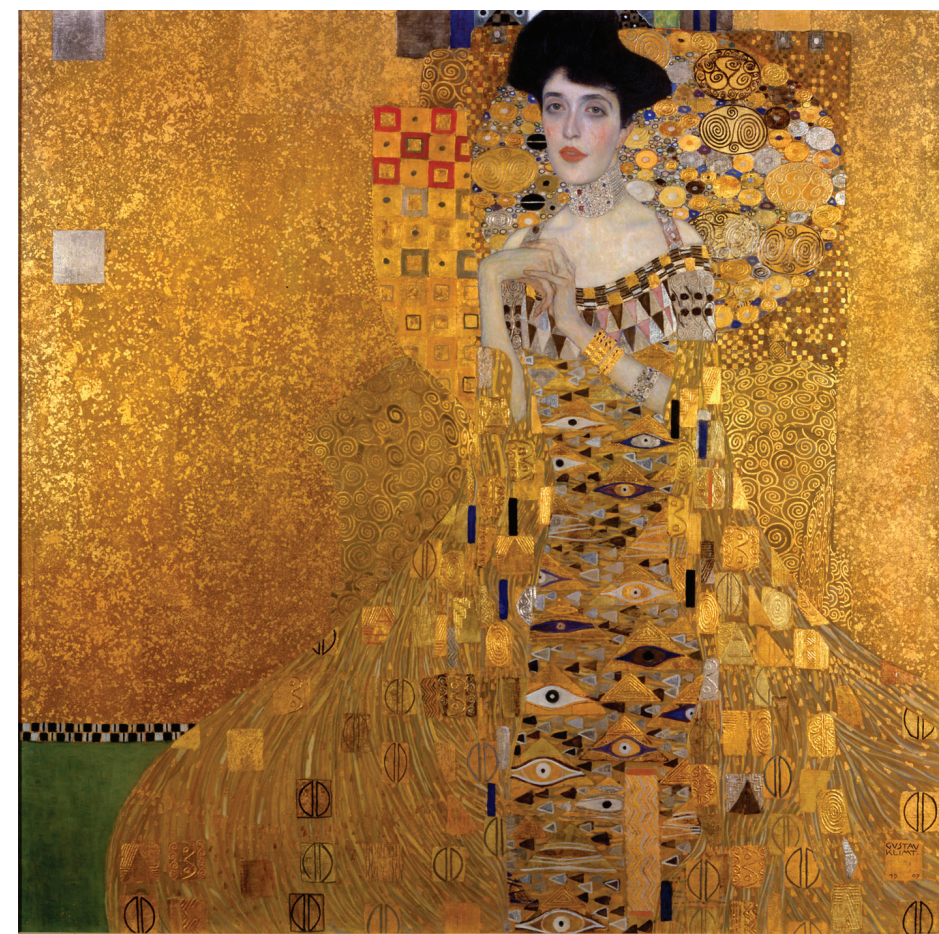

[Figura 4] KLIMT, Gustav. Retrato de Adele Bloch-Bauer I.

Óleo e ouro sobre tela, Nova lorque: Neue Galerie, $138 \mathrm{~cm} \times 138 \mathrm{~cm}$, 1907. [Imagem@Wikimedia Commons] 
No verso do estandarte da Coroação foi montada a pintura Stigmatization of St. Francis ${ }^{12}$, considerada por Christiansen uma obra mais revolucionária e significativa que a própria Coroação, pelo tratamento da luz, pela construção do cenário e pela exposição da arquitetura da capela romana em detalhes "quase arqueológicos". Se Stigmatization pode ser situada como em uma fase onde já explora luz e cenários construídos de forma naturalista, a Coronation busca a composição iconográfica em uma tradição antiga e já anacrônica para sua época, em Cione ${ }^{13}$, um pintor de uma geração anterior e uma imagem de mais de cinquenta anos.

Quando nos perguntamos porque Centile se interessou por uma imagem de cinquenta anos, enquanto a mais elegante e recente Coroação da Virgem de Lorenzo Monaco, agora em Uffizi ${ }^{14}$, passava despercebida, a resposta parece ser que apenas em Cione Centile poderia encontrar figuras solidamente construídas e combinadas com uma riqueza da ornamentação da superfície. Poucos fatos são mais significativos do que a recusa às formas duras e oscilantes do Cótico Internacional, mas Gentile compartilhava essa escolha com o jovem Masaccio, cujo primeiro retábulo, São Ciovenale em Cascia, datado de $1422^{15}$, é estritamente cionesco na rígida apresentação de suas figuras modeladas em planos cuidadosamente definidos. ${ }^{16}$

\section{Klimt}

Klimt tem formação clássica na Escola de Artes Decorativas e, desde cedo dedica-se a pintar murais e afrescos, sob encomenda das mais diversas instâncias do poder de sua época. O Beijo faz parte da sua fase dourada, onde trabalhou com folha de ouro e outros metais para efeitos de fusão em seus quadros. Sua busca já o havia levado à Itália, em 1903, quando visitou os vitrais de Veneza e Ravena, buscando as formas de impressão e acabamento que puderam dar tanta resistência às imagens, dedicando-se a uma pesquisa original de ligas e impressões de padrões, aliando a pesquisa

\footnotetext{
12 FABRIANO, Gentile da. Stigmatization of St. Francis. Têmpera e ouro sobre madeira, $93 \mathrm{~cm} \times 64.1 \mathrm{~cm}$. Milão: Caminati Collection, 1420 . — Figura 3 -

13 The Coronation of the Virgin. Egg tempera on wood, $206.5 \times 113.5 \mathrm{~cm}$. London: National Gallery, 1370. [Disponível em: https://www.nationalgallery. org.uk/paintings/jacopo-di-cione-and-workshop-the-coronation-of-the-virgin-central-main-tier-panel].

14 MONACO, Lorenzo. Coronation of the Virgin. Tempera on panel, 350cm X 450cm. Florence: Uffizi Gallery, 1414. [Disponível em: https:// artsandculture.google.com/asset/coronation-of-the-virgin/4wCwlhQqTqCArw].

15 MASACCIO. Panel, San Pietro (Florence): Cascia di Reggello, $110 \times 65$ cm (central), $88 \times 44 \mathrm{~cm}$ (each wing). 1409. [Disponível em: https://www. wga.hu/html_m/m/masaccio/z_panels/giovenar.html].

16 CHRISTIANSEN, Keith. The Coronation of the Virgin by Gentile Da Fabriano. página 8 ["When we ask ourselves why Gentile should have been interest-ed in an image some fifty years old while Lorenzo Monaco's more fashionable and recent Coronation of the Virgin now in the Uffizi apparently passed unnoticed, the answer must be that only in the Cione could Gentile find solidly constructed figures combined with a wealth of surface ornamentation. Few facts are more significant than this repudiation of the hard, swinging forms of Florentine International Cothic, but Centile shared this choice with the young Masaccio, whose earliest al-tarpiece from S. Giovenale in Cascia, dated 1422 , is strictly Cionesque in the rigid presentation of its figures modelled in carefully defined planes."].
} 
do meio físico e bruto com a busca de uma técnica de pintar que acompanhasse essa originalidade.

Outro contato que teve com uma estética próxima à de Fabriano foi quando contratado pelo banqueiro e empresário belga Adolphe Stoclet (1871-1949), sem dúvida um ícone do poder e pujança financeira e da militância do capitalismo liberal, juntamente com outros renomados arquitetos e artesãos, para pintar os afrescos e painéis do Stoclet Palace, cuja construção durou de 1905 a 1911. Sob esse período de contratação produziu obras de grande impacto e sucesso, arrematadas antes mesmo do término: O Beijo e, particularmente, Retrato de Adele Bloch-Bauer ${ }^{17}$, onde apresenta rasgos figurativos irrompendo de uma geometria que o circunda como um papel de parede de primeiro plano. Passa a utilizar também, sistematicamente, as folhas de ouro e outras técnicas de ligas de metais, como prata e chumbo.

Stoclet, seu contratador, além de ter demonstrado interesse por esse contemporâneo pintor, do qual encomendara obras no auge de sua fase dourada e quem apoiou na sua carreira, também tinha interesse pela estética pré-renascentista, particularmente por um estilo conhecido como Gótico Internacional, e tinha em seu acervo, por exemplo, The Archangel Michael ${ }^{18}$, de Pellegrino di Giovanni, um quadro que tem por modelo e influência a técnica de Centile da Fabriano.

Como que de forma especular ao movimento de Centile, Klimt caminha do figurativo para o abstrato como mensagem de renovação e crise, utilizando-se do "repertório técnico do artesão medieval"19 para criar uma superfície variada, transitando do "naturalismo de larga escala" para uma forma híbrida, onde o abstracionismo revela aspectos, rasgos de um figurismo que não se propõe a resolver-se como retrato, mas como metáfora irruptiva.

\section{Materialidade: uso do OURO}

O ouro como elemento da composição material dos trabalhos, sob forma de folhas de ouro, é por si não penas um símbolo, mas um meio físico de acabamento que se impõe como um lastro efetivo de exuberância, um aparato de valor: não é qualquer um que utiliza folhas de ouro em suas telas e ambos o fizeram por serem muito bem sucedidos em seus tempos.

Gentile e Klimt dedicaram grande parte de suas vidas profissionais a pintar painéis e murais

\footnotetext{
17 KLIMT, Gustav. Retrato de Adele Bloch-Bauer I. Em óleo e ouro sobre tela, $138 \mathrm{~cm} \times 138 \mathrm{~cm}$. Nova lorque: Neue Galerie, 1907 . — Figura 4 -

18 GIOVANNI, Pellegrino di. Archangel Michael. Tempera on panel, $100 \mathrm{~cm} \times 37.5 \mathrm{~cm}$. Boston: Museum of Fine Arts, 1428 . [Disponível em: https:// collections.mfa.org/objects/34016].

19 Ver citação de Christiansen, nota 8, página
} 
sob encomenda de instituições religiosas, educacionais, privadas e públicas e foram reconhecidos como artistas que conseguiam expressar uma auto imagem exuberante e exultante de suas contemporaneidades: do poder e exuberância da Igreja, onde Gentile compõe um estandarte; da ardente burguesia rica da Áustria, onde Klimt se torna símbolo cunhado em moeda. O ouro é matéria prima das duas, um lastro efetivo de valor estético.

\section{Representação: utilização de PADRÕES}

Decodificação e composição dos territórios pictóricos de forma que os preenchimentos sejam compostos por formas básicas e regulares, responsáveis pelo efeito de volume e densidade, velando o corpo humano como um papel de parede que o cobrisse. Uma bem-sucedida convivência entre o figurativo e o abstrato que dá um caráter diagramático nos quadros: são figurativos, mas figurativos em alguns territórios, disputando sua aparição com territórios diagramados com preenchimento de padrões que ocupam o primeiro plano.

Particularmente os rostos, onde os pintores parecem compartilhar um mesmo humor tonal, destacam-se nas duas pinturas como que abrindo um rasgo no papel de parede muito bem ajustado que lhe anuncia uma dupla existência visível e invisível, revelando uma continuidade de um corpo que se supõe estar ali, mas velado.

Em uma das cenas, a de Gentile, por definição, deveriam ser corpos pudicamente assexuados: já que entre mãe e filho e, ademais, santos. Na outra, de Klimt, vem expresso o despudorado, não sem problemas com alguns conservadores em sua época. Mas de uma certa forma em ambas revelando um gesto análogo, acobertando uma sexualidade latente que deveria explodir, mas é emoldurada por padrões de melancolia e cansaço, que parecem brotar das mãos femininas das pinturas, tão diferentes das mãos masculinas, que detém o poder de conceder e segurar firmemente, constringindo o rosto.

Nesse sentido, mais paradigmática ainda é a aproximação da técnica de Gentile e Gustav Klimt, no Retrato de Adele Bloch-Bauer ${ }^{20}$, não apenas na estamparia e padronagem como elementos constitutivos, mas também a utilização da aplicação de ouro e na modelagem da fisionomia e do rosto, que se destaca do conjunto por sua proposta de naturalidade contrita, assim como o rosto da Virgem na Coroação, projetando o mesmo ângulo e padrão tonal resignado.

20 Retrato de Adele Bloch-Bauer I. - Figura 4- 
Normatividade: o enquadramento da mulher coroada

Um êxtase contrito e resignado: uma face semelhante que irrompe por entre padrões - com pudor ou despudorada - mas mantido em um mesmo ângulo, sob uma mesma mão masculina que aponta em riste com seus dedos onde se destacam, sutilmente, o indicador e o dedo médio, 0 gesto ancestral de validação, homenagem e contrição. As mãos femininas, sobre o peito, lembram um certo cansaço: nos dois quadros os dedos esguios pousam entre a exaustão e o êxtase.

A configuração do ângulo do rosto é mantida por um gesto de contrição amorosa. Os dois dedos da mão em riste podem ser de benção, de aceitação ou de apropriação da mulher coroada que se quer contrita. A continuidade das mãos masculinas de um quadro a outro parecem fotogramas de uma forma ancestral de coroar e constranger.

Ambos os pintores estão envolvidos nas crises de suas épocas: a crise do Renascimento, na virada para o século XV e a crise das Vanguardas, da virada para o XX. A dialética entre o figurativo e o abstrato aparece como questão central nas crises e inerentes nas estéticas das obras aqui interpretadas, onde convivem como em litígio: o figurativo irrompe ou rasga a cobertura de um primeiro plano que funciona como um papel de parede feito de padrões.

A força de emergência vem do próprio corpo, ora um rosto, ora mãos ou pés, que irrompem e tentam se arremessar, mas são mantidos emoldurados pelo valor em ouro que tem por contrapeso, pelos padrões como medida de sua expressividade e pela consagração do corpo feminino coroado e contrito.

Um mesmo problema que, enfrentado sob diversos aspectos, nos dá um lastro de humanidade na ideia de história da arte, onde os valores se chocam violentamente como corpos, o corpo concreto da obra como valor abstrato do dinheiro e o valor idealizado e figurado em aspectos do corpo humano, entretanto concreto e contrito sob seu papel de parede, de ouro. 


\section{Referências bibliográficas}

CHRISTIANSEN, Keith. "The Coronation of the virgin by Centile da Fabriano". In: J. Paul Getty Museum Journal: Volume 6-7/1978-1979. Los Angeles: Getty Publications, 1979. [Disponível em: http://www.getty.edu/publications/virtuallibrary/0892360186.html].

CIONE, Jacopo di (Florence c.1365-1398|1400). The Coronation of the Virgin. Egg tempera on wood, $206.5 \times 113.5 \mathrm{~cm}$. London: National Gallery, London: National Gallery, 1370. [Disponível em: https://www.nationalgallery.org.uk/paintings/ jacopo-di-cione-and-workshop-the-coronation-of-the-virgin-central-main-tier-panel].

FABRIANO, Gentile da. Adoration of the Magi. Têmpera e ouro sobre madeira, $300 \mathrm{~cm} \times 282 \mathrm{~cm}$. Florence: Galleria degli Uffizi, 1423 [Disponível em: [https://www.uffizi.it/en/artworks/adoration-of-the-magi].

FABRIANO, Gentile da. Coronation of the Virgin. Têmpera e ouro sobre madeira, $93 \mathrm{~cm} \times 64.1 \mathrm{~cm}$. Los Angeles: The ]. Paul Getty Museum, 1420. — Figura 1

FABRIANO, Gentile da. Coronation of the Virgin with Saints. Tempera on panel, $157,2 \mathrm{~cm} \times 79,6 \mathrm{~cm}$ central panel; $117,5 \mathrm{~cm}$ $\times 40 \mathrm{~cm}$ lower side panels; $48,9 \mathrm{~cm} \times 37,8 \mathrm{~cm}$ upper side panels. Milão: Pinacoteca di Brera, Room XXII, 1408 [Disponível em: https://pinacotecabrera.org/en/collezione-online/opere/valle-romita-polyptych/].

FABRIANO, Gentile da. Stigmatization of St. Francis. Têmpera e ouro sobre madeira, $93 \mathrm{~cm} \times 64.1 \mathrm{~cm}$. Milão: Caminati Collection, 1420 - Figura 3 -

GIOVANNI, Pellegrino di. Archangel Michael. Tempera on panel, $100 \mathrm{~cm} \times 37.5 \mathrm{~cm}$. Boston: Museum of Fine Arts, 1428 . [Disponivel em: https://collections.mfa.org/objects/34016].

KLIMT, Gustav. O beijo . Óleo e folha de ouro sobre tela, $180 \mathrm{~cm} \times 180 \mathrm{~cm}$. Viena: Österreichische Galerie Belvedere, 1907 e 1908. - Figura 2-

KLIMT, Gustav. Retrato de Adele Bloch-Bauer I. Em óleo e ouro sobre tela, $138 \mathrm{~cm} \times 138 \mathrm{~cm}$. Nova lorque: Neue Galerie, 1907. - Figura 4 -

MASACCIO. San Giovenale Triptych, $110 \mathrm{~cm} \times 65 \mathrm{~cm}$ (central), $88 \mathrm{~cm} \times 44 \mathrm{~cm}$ (each wing). San Pietro (Florence): Cascia di Reggello, 1409. [Disponível em: https://www.wga.hu/html_m/m/masaccio/z_panels/giovena1.html].

MONACO, Lorenzo. Coronation of the Virgin. Tempera on panel, $350 \mathrm{~cm}$ X 450cm. Florence: Uffizi Gallery, 1414. [Disponível em: https://artsandculture.google.com/asset/coronation-of-the-virgin/4wCwlhQqTqCArw]. 